\title{
REVIEW
}

\section{Metabolic and hormonal remodeling of colorectal cancer cell signalling by diabetes}

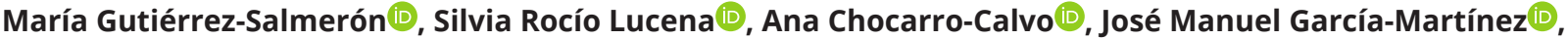 \\ Rosa M Martín Orozco and Custodia García-Jiménez
}

1Area of Physiology, Faculty of Health Sciences, University Rey Juan Carlos, Alcorcón, Madrid, Spain

Correspondence should be addressed to C García-Jiménez: custodia.garcia@urjc.es

\begin{abstract}
The existence of molecular links that facilitate colorectal cancer (CRC) development in the population with type 2 diabetes (T2D) is supported by substantial epidemiological evidence. This review summarizes how the systemic, metabolic and hormonal imbalances from T2D alter CRC cell metabolism, signalling and gene expression as well as their reciprocal meshing, with an overview of CRC molecular subtypes and animal models to study the diabetes-CRC cancer links. Metabolic and growth factor checkpoints ensure a physiological cell proliferation rate compatible with limited nutrient supply. Hyperinsulinaemia and hyperleptinaemia in prediabetes and excess circulating glucose and lipids in T2D overcome formidable barriers for tumour development. Increased nutrient availability favours metabolic reprogramming, alters signalling and generates mutations and epigenetic modifications through increased reactive oxygen species and oncometabolites. The reciprocal control between metabolism and hormone signalling is lost in diabetes. Excess adipose tissue at the origin of T2D unbalances adipokine (leptin/ adiponectin) secretion ratios and function and disrupts the insulin/IGF axes. Leptin/ adiponectin imbalances in T2D are believed to promote proliferation and invasion of CRC cancer cells and contribute to inflammation, an important component of CRC tumourigenesis. Disruption of the insulin/IGF axes in T2D targets systemic and CRC cell metabolic reprogramming, survival and proliferation. Future research to clarify the molecular diabetes-CRC links will help to prevent CRC and reduce its incidence in the diabetic population and must guide therapeutic decisions.
\end{abstract}
Key Words
- diabetes and colorectal cancer
- glucose and lipids
- insulin
- leptin and adiponectin
- mouse models

\section{Introduction}

Diabetes affects $9 \%$ of the adult population worldwide with a prevalence predicted to double between 2010 and 2030, following ageing and obesity-linked lifestyle changes (García-Jiménez et al. 2016). Type 2 diabetes (T2D) represents about $90 \%$ of all diabetes and usually develops slowly from obesity whereas type 1 diabetes (T1D) is rare and develops suddenly, subsequently to autoimmune responses against beta-cells. Many T2D hallmarks are derived from obesity and both are epidemiologically associated with an increased incidence and morbidity of certain cancers (García-Jiménez et al. 2016, Gutiérrez-Salmerón et al. 2017). T2D is an endocrine disease characterized by defects in metabolism (hyperglycaemia, hyperlipidaemia), hormonal signalling (insulin, leptin and adiponectin), immunity and microbiome composition. Despite resemblances, T1D and T2D metabolic, signalling and immune alterations differ; not surprisingly the epidemiological association of 
T1D and T2D to cancers diverges extensively, with T2D more widely associated to cancer (Gutiérrez-Salmerón et al. 2017). Among all cancers, T2D positively associates to colorectal cancer (CRC) and correction for obesity (as a major confounding factor) does not decrease the magnitude of the T2D-CRC association: relative risk of 1.29; CI (1.21-1.34). Since CRC is the third most commonly diagnosed malignancy and the second leading cause of cancer-death (Guinney et al. 2015), studying the selected T2D population represents an opportunity to study CRC tumourigenesis for prevention. This review focusses on the potential contribution of metabolic and hormonal alterations in T2D to CRC; the contribution of immune and microbiome alterations are reviewed in Gutiérrez-Salmerón et al. (2021).

Improved detection and increased lifespan might explain recent increases in CRC incidence. However, the alarming rise of CRCs at younger ages (before 50 years) (Vera et al. 2019) annoyingly reflects the pandemics of obesity and diabetes, suggesting that lifestyles associated to obesity and T2D, high fat diets (HFD) and sedentarism may drive increased CRC incidence. Independent contribution from obesity and T2D is supported by their independent association to different cancers (GutiérrezSalmerón et al. 2017, 2021).

Most colorectal cancers arise from neoplastic precursor lesions or polyps in a process that begins with aberrant crypts and needs 10-15 years to progress to CRC, evolving as adenoma-carcinoma (70-90\% of CRC) or serrated neoplasia (10-20\% of CRC) characterized by metabolic transformation and multiple genome alterations, potentially associated to T2D (Fig. 1) (Miranda-Gonçalves et al. 2018, Dekker et al. 2019).

CRCs are classified into tumour-node-metastasis (TNM) stages I to IV, attending to the tumour size, degree of lymph node infiltration and presence of metastasis (Wittekind 2015), to guide the choice of treatment: surgery, radiotherapy, or chemotherapy. Chemotherapy choice requires further refinement in CRCs classification and prompted the establishment of four CRC molecular subtypes (CMSs) by the CRC Subtyping Consortium after jointly analysing data from independently developed algorithms (Guinney et al. 2015, Stastna et al. 2019). Clinical and prognostic CRCs aspects combined with molecular signatures, summarized in Fig. 2, established CMS1 (MSI immune), CMS2 (canonical), CMS3

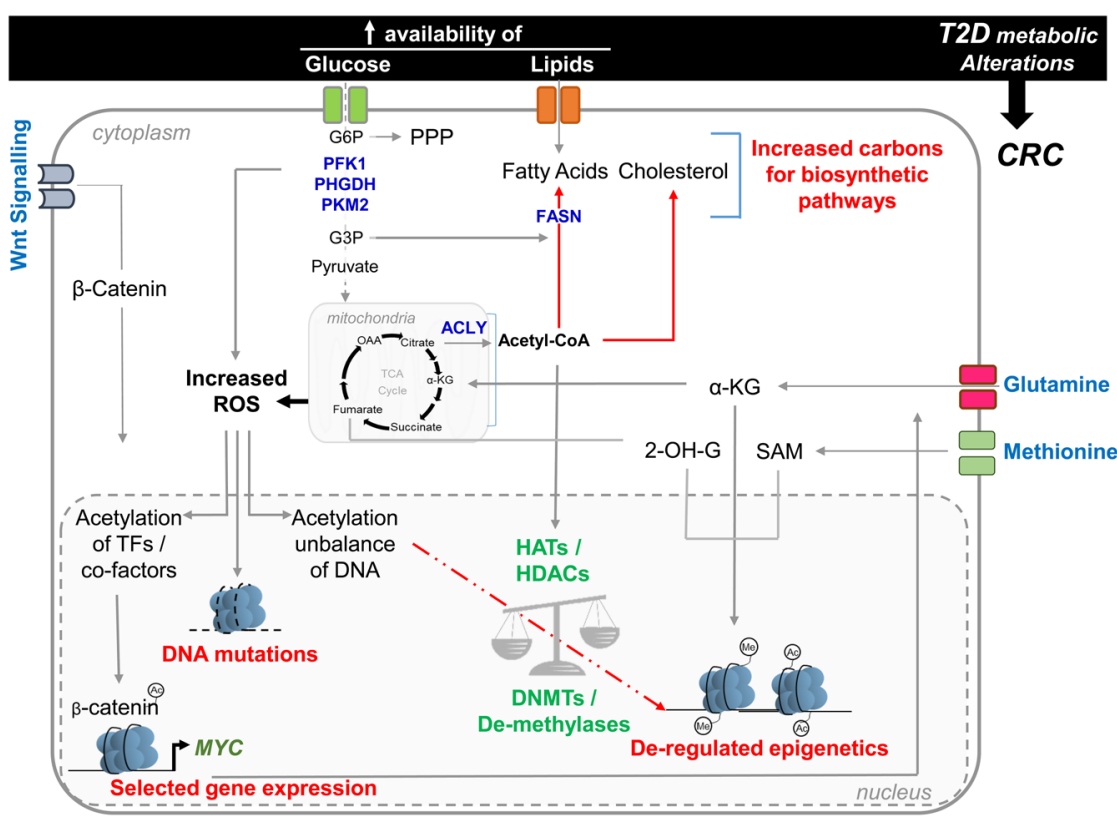

https://erc.bioscientifica.com https://doi.org/10.1530/ERC-21-0092
(C) 2021 Society for Endocrinology Published by Bioscientifica Ltd. Printed in Great Britain

\section{Figure 1}

The metabolic environment of T2D favours reprogramming in colon cancer cells. Increased availability of glucose in T2D enhances Wnt/ $\beta$ catenin signalling, promotes ROS accumulation that induces DNA mutations and alters the acetylation balance, impacting oncogenes, metabolic enzymes (blue), and epigenome modifiers (green), creating a positive feedback loop fuelled by T2D metabolic disorders. Activated oncogenes such as Myc impact metabolism through increased glucose and glutamine uptake, altered expression/activity of metabolic enzymes that promote glycolysis, mitochondrial reprogramming and dysregulation of lipid metabolism, a metabolic transformation that supports CRC development and progression. T2D metabolic environment regulates HATs, HDACs, DNMTs and demethylases to impact the acetylation and methylation balances causing epigenetic modifications that feed CRC. 2-OH-G, 2-hydroxyglutate; $\alpha K G$, $\alpha$-ketoglutarate; ACLY, ATP citrate lyase; DNMTs, DNA methyltransferase; FASN, fatty acid synthase; G3P, glyceraldehyde-3phosphate; G6P, glucose-6-phosphate; HATs, histone acetyltransferases; HDACs, histone deacetylases; OAA, oxaloacetate; PFK1, phosphofructokinase 1; PHGDH, phosphoglycerate dehydrogenase; PKM2, pyruvate kinase isozyme M2; PPP, pentose phosphate pathway; ROS, reactive oxygen species; SAM, S-adenosylmethionine; TCA cycle, tricarboxylic acid cycle. 


\begin{tabular}{|c|c|c|c|c|c|}
\hline \multicolumn{2}{|c|}{ Subtype } & CMS1 & CMS2 & CMS3 & CMS4 \\
\hline \multirow[b]{2}{*}{$\begin{array}{c}\text { Molecular } \\
\text { Characteristics }\end{array}$} & Mutations & $\begin{array}{l}\text { MSH6, ATM, PTEN, } \\
\text { TFGBR2, BRAF }\end{array}$ & $\begin{array}{c}\text { APC, KRAS, TP53, } \\
\text { SMAD4, PI3KCA, WNT, } \\
\text { MYC }\end{array}$ & $\begin{array}{c}\text { APC, KRAS, TP53, } \\
\text { SMAD4, PI3KCA }\end{array}$ & $\begin{array}{c}\text { APC, KRAS, TP53, } \\
\text { SMAD4, PI3KCA, TFGB }\end{array}$ \\
\hline & Pathways & $\begin{array}{l}\text { Macroenvironment: } \\
\text { upregulated immune } \\
\text { pathways (Th1, } \\
\text { cytotoxic T cell, PD-1) } \\
\text { and NK cell infiltration }\end{array}$ & $\begin{array}{l}\text { Upregulation of } \\
\text { canonical pathways } \\
\text { (WNT and MYC) }\end{array}$ & $\begin{array}{c}\text { Upregulation of } \\
\text { metabolic pathways }\end{array}$ & $\begin{array}{l}\text { Upregulated EMT, TGF- } \\
\beta \text {, matrix remodelling, } \\
\text { angiogenesis and } \\
\text { complement activation }\end{array}$ \\
\hline \multicolumn{2}{|l|}{ Target/Therapy } & $\begin{array}{c}\text { DNA } \\
\text { replication/FOLFOX } \\
\text { Immune checkpoint / } \\
\text { PD-1 inhibitors }\end{array}$ & $\begin{array}{l}\text { DNA replication/ } \\
\text { Standard adjuvant } \\
\text { chemotherapy } \\
\text { (5Fluorouracil-based) }\end{array}$ & $\begin{array}{l}\text { KRAs mut. / MEK-RAF } \\
\text { inhibitors } \\
\text { KRAS not mut. / anti- } \\
\text { EGRF }\end{array}$ & $\begin{array}{l}\text { Angiogenesis and } \\
\text { stromal elements }\end{array}$ \\
\hline \multicolumn{2}{|c|}{ Epigenomic features } & High Methylation & - & Low Methylation & Low Methylation \\
\hline \multicolumn{2}{|l|}{ CRC cases (\%) } & 14 & 37 & 13 & 23 \\
\hline \multicolumn{2}{|c|}{ Aggressivity/ Survival } & $\begin{array}{c}\text { Lower survival after } \\
\text { relapse }\end{array}$ & $\begin{array}{l}\text { Higher survival after } \\
\text { relapse }\end{array}$ & - & $\begin{array}{l}\text { Lower survival after } \\
\text { relapse }\end{array}$ \\
\hline \multirow{2}{*}{$\frac{\text { Models }}{\text { (examples) }}$} & In vitro & LOVO, HCT 116, SW48 & SW948, LS1034, HT55 & HT-29, LS-174T, LS-513 & Caco-2, LS-123, CaR-1 \\
\hline & In vivo & $\mathrm{Braf}^{\mathrm{V} 600 \mathrm{E}}$ & $\mathrm{Apc}^{\mathrm{Min}}$ & $\mathrm{Apc}^{\mathrm{Min}} \mathrm{K}-\mathrm{ras}^{\mathrm{Asp} 12} \mathrm{Ah}-\mathrm{Cre}$ & - \\
\hline
\end{tabular}

\section{Figure 2}

Summary of colorectal cancer molecular subtypes (CMS) signatures. CRC is classified into four molecular subtypes (CMS1 to CMS4) according to molecular features (including mutations, aberrant signalling and epigenomic changes), clinical features of relapse or survival and frequency. Specific animal and cellular models for each subtype are highlighted at the bottom. (FOLFOX), fluorouracil, leucovorin, and oxaliplatin; (-), not described.

(metabolic) and CMS4 (mesenchymal) to improve stratification. Later, CMSs were correlated with particular microbiome and immune patterns, as discussed in Gutiérrez-Salmerón et al. (2021). Molecular signatures in CMSs represent the most frequent mutations and were suggested to derive from distinct initiating cells. CMSassociated mutations occur in adenomatous polyposis coli (APC), found in $\sim 80 \%$ of cases; EGF receptor (EGFR), in $\sim 60 \%$, KRAS, about 40\%, transforming growth factor beta (TGFB), $\sim 30 \%$ and phosphatidylinositol 3-kinase (PI3K), 14\%. These mutations drive aberrant activation of the Wnt, PI3K, JAK/Stat and mitogenactivated proteins kinases (MAPK) signalling pathways, Fig. 2. Recently, Hippo and Notch pathway components have been related as over-represented in CMS4 and missrepresented in CMS2 (Mouillet-Richard \& Laurent-Puig 2020). YAP/TAZ, a crosstalk node between the Hippo and Wnt signalling pathways regulates glucose, lipid, and amino acid metabolism, as well as mitochondrial biogenesis (Koo \& Guan 2018). Reciprocally, deregulated levels of circulating glucose and lipids, insulin and leptin/adiponectin in T2D modulate these CRCassociated signalling pathways. High glucose enhances Wnt and PI3K signalling to induce MYC which represents a dominant contribution to CMS2 (canonical). Aberrant insulin/IGF1 signalling in T2D alters not only PI3K but also MAPK to dysregulate the metabolism of carbohydrates, lipids and glutamine linking it to CMS3 (metabolic). Increased leptin/adiponectin ratios in T2D enhance JAK/ STAT and inflammation and may link T2D to CMS1 (immune) which exhibit increased NK cell infiltration and upregulated immune pathways reminiscent of adipose tissue infiltration in obesity and T2D. Lastly, increased circulating lipids, which enhance epithelial-tomesenchymal transition (EMT) may link T2D to CMS4, see Fig. 2. There are other mutations co-occurring in CRC that affect TP53 (48-59\%), DNA repair proteins (Koncina et al. 2020) and others. We review here how metabolic and hormonal alterations from T2D might impact these signalling pathways in CRC. Relevant mice models to study T2D specific effects on particular CMSs are discussed and summarized in Fig. 2. (c) 2021 Society for Endocrinology Published by Bioscientifica Ltd. Printed in Great Britain 


\section{Remodelling CRC cell signalling by metabolism-related factors from T2D}

Metabolic transformation of CRC cells encompasses enhanced aerobic glycolysis and mitochondrial reprogramming. Deregulated carbohydrate and lipid metabolism in T2D provide increased availability of glucose and lipids to cancer cells favouring metabolic transformation. Excess nutrients allow cancer cells to overcome growth inhibition checkpoints and apoptotic signalling, leading to enhanced survival, proliferation and morphological changes required for invasion and metastasis (De Berardinis \& Chandel 2016).

\section{Increased nutrient availability in T2D favours metabolic transformation}

\section{Deregulated glucose metabolism in T2D favours aerobic glycolysis in CRC cells}

Aerobic glycolysis is enhanced in CRC cells independently of oxygen availability (Warburg 1956) and requires increased glucose uptake. Correspondingly, augmented expression and/or exhibition of glucose transporters such as GLUT1 is associated with poor CRC prognosis (Ancey et al. 2018). T2D provides increased glucose availability for cancer cells, an advantage to provide fast energy and carbons through enhanced glycolysis. Not surprisingly, GLUT1 expression and translocation to the plasma membrane are governed by PI3K and RAS-MAPK signalling pathways, whose signalling is altered in both T2D and CRC. In CRC cells, high glucose enhances Wnt signalling (Chocarro-Calvo et al. 2013, García-Jiménez et al. 2014) to induce MYC expression, which reciprocally enhances glycolysis. MYCenhanced expression of GLUT1 and glycolytic enzymes (Li \& Simon 2013) such as phosphofructokinase 1 (PFK1), phosphoglycerate dehydrogenase (PHGDH) and pyruvate kinase M2 (PKM2), feeds back positively. Glucose carbons are deviated to fuel the anabolic synthesis of non-essential amino acids and purines/pyrimidines through the pentose phosphate pathway (PPP), providing metabolic precursors for protein and DNA biosynthesis to support proliferation. Regeneration of NADPH through the PPP provides the cofactor needed for lipid biosynthesis and detoxification of reactive oxygen species (ROS), reducing membrane and genetic lesions (Fig. 1) (Sciacovelli et al. 2014). Hyperglycaemia also increases hexosamine pathway towards glycosylation that enhances transcription of c-Myc, modulates cell signalling and epigenetics to promote tumour development (Vasconcelos-dos-Santos et al. 2017, Akella et al. 2019). Hyperglycaemia also increases diacylglycerol and ROS levels to induce PKC that stimulates cytokine production and angiogenesis (Nishikawa et al. 2000).

\section{Deregulated glucose metabolism in T2D favour mitochondrial reprogramming in CRC cells}

In nonproliferating cells, glycolysis renders pyruvate, converted by mitochondrial pyruvate dehydrogenase (PDH) to acetyl-CoA, which enters the tricarboxylic acids (TCA) cycle. In contrast, CRC cells deviate glucose carbons towards anabolic pathways, diminishing their contribution to the TCA cycle and the subsequent flow of reducing equivalents to oxidative phosphorylation (OXPHOS) (Porporato et al. 2018). Wnt-mediated inhibition of PDH through its kinase PDK1 contributes to the reduced entry of glucose carbons; cancer cell mitochondria adapt by using anaplerotic pathways to supply TCA intermediaries. As such, pyruvate carboxylase converts pyruvate into oxaloacetate. Enhanced glutamine uptake and glutaminolysis provide another TCA intermediate: $\alpha$-ketoglutarate $(\alpha-\mathrm{KG})$ (Porporato et al. 2018). Anaplerosis allows mitochondria to contribute to epigenetic remodelling of CRC cells by supplying metabolites that modify the activity of epigenetic 'writer' enzymes such as methyl- or acetyl-transferases. For example, TCA-derived citrate is transported to the nucleus where ATP-citrate lyase (ACLY) converts it into oxalacetate (OAA) and acetyl-CoA to provide acetyl groups for acetylation of histones or other proteins (MirandaGonçalves et al. 2018). TCA-derived $\alpha$-KG levels, altered by MYC-driven glutamine transporters and glutaminase expression in CRC cells (Li \& Simon 2013), control DNA and histone methylation. Glutamine metabolism also ensures alternative carbon and nitrogen sources for proteins and nucleotides synthesis and the conversion of glutamine to glutamate and $\alpha$-KG generates NADPH, needed for lipid synthesis and ROS detoxification being essential to maintain cancer cell viability (Sciacovelli et al. 2014). Thus, mitochondrial reprogramming in cancer cells supports evasion of apoptosis, energetic metabolism, and epigenetic modifications.

Mitochondrial dynamics reflect OXPHOS capacity with fusion/fission imbalances driving mitochondrial dysfunction. Mitochondrial fission increases in highly proliferative CRC cells, driving mitochondrial dysfunction yet providing means for (i) ATP production; (ii) refilling TCA intermediaries (towards anabolic processes) and (iii) detoxification of ROS, that leak from uncoupled mitochondrial respiration contributing to genetic mutations, epigenetic modifications and chromosomal (c) 2021 Society for Endocrinology Published by Bioscientifica Ltd. Printed in Great Britain 
instability (Sciacovelli et al. 2014, Porporato et al. 2018). Interestingly, mitochondrial dysfunction appears in T2D patients, in skeletal muscle and beta-pancreatic cells (Dai \& Jiang 2019). Distinct mitochondrial adaptations characterize different cancer cell phenotypes in tumours (e.g., metastatic, proliferative, stem cells) and distinct tissues may adapt differently in T2D patients. Further research will reveal potential mitochondrial adaptations to the metabolic stress imposed by T2D in colonic epithelial cells.

\section{Deregulated lipid metabolism favours mitochondria reprogramming and EMT in CRC cells}

Increased circulating free fatty acids (FFA) and cholesterol are metabolic hallmarks of T2D. Lipids and cholesterol play critical roles in membrane formation, structure and function, signalling and energy storage (Koundouros \& Poulogiannis 2020). Not surprisingly, cancer cells exhibit increased cellular uptake and de novo lipid biosynthesis. Therefore, deregulated lipid metabolism in T2D might support tumour development. Enhanced lipid biosynthesis sustained by upregulation of the rate limiting enzymes fatty acid synthase (FASN) and acylCoA synthetase (ACSL) correlates with poor prognosis (Koundouros \& Poulogiannis 2020) EMT, invasion and metastasis in CRC cells (Beloribi-Djefaflia et al. 2016). High FASN expression in invasive CRC cells correlates with enhanced mitochondrial respiration, consistent with preferential use of endogenously synthesized lipids to fuel energy demands during metabolic stress such as invasion/ metastasis. Glucose enhances Wnt and MYC-dependent FASN expression and PI3K/Akt activation of mTORC1 to regulate fatty acid metabolism in CRC cells through the expression of critical lipogenic enzymes, including also ACSL, short-chain family member 2 (ACCSS2) and ACLY (Koundouros \& Poulogiannis 2020).

Circulating cholesterol levels are decreased in CRC compared to healthy patients (Zhang et al. 2014), whereas T2D patients often present hypercholesterolaemia (low HDL-C and high LDL-C). Cancer cells store cholesterol in lipid droplets to be used for proliferation and migration. Plasma lipid profile modifications in CRC could reflect an adaptive mechanism for cancer cells to reduce cholesterol levels available for normal cell proliferation. High circulating cholesterol in T2D may then feed CRC progression. An important, yet, unanswered question is whether CRC reduces plasma levels of cholesterol in T2D patients.

Related to lipids, Vitamin D is a cholesterol derivative whose deficiency is epidemiologically associated to both
T2D (Berridge 2017) and CRC (Lee et al. 2011). Vitamin $\mathrm{D}$ and cholesterol levels inversely correlate in T2D (Jiang et al. 2019). Vitamin D bound to its nuclear receptor antagonizes Wnt signalling at several levels to prevent proliferation and EMT in CRC (Ferrer-Mayorga et al. 2019). Thus, Vitamin D deficiency in T2D releases Wnt signalling brakes, leaving CRC cells undefended and requires future studies.

Lastly, although this review focuses on changes in tumour cells, it should be added that excess circulating glucose and lipids will also alter the tumour micro- and macroenvironment, indirectly impacting tumour biology. For example, endothelial cell alterations by hyperglycaemia critically influence angiogenesis at tumour microenvironment (da Cunha et al. 2019); immune defects linked to the metabolic environment of diabetes will impact tumour cell biology at the macroenvironment (Gutiérrez-Salmerón et al. 2020, 2021).

In summary, excess circulating glucose and lipids in T2D: (i) modulate several CRC-related signalling pathways; (ii) promote metabolic reprograming and (iii) generate intermediaries that alter gene expression through genetic lesions and epigenetic modifications. Glucoseenhanced Wnt induces MYC in CRC cells, to increase the uptake of glucose, glutamine and FFA, as well as glycolysis, glutaminolysis and fatty acid synthesis, creating a feed forwards cycle that supports enhanced proliferation and invasion (Fig. 1) through metabolic reprogramming. This includes (i) enhanced aerobic glycolysis and glucose carbon deviation towards the PPP and serine/glycine pathways; (ii) reduced glucose carbon flow to the TCA cycle; (iii) enhanced glutamine uptake; (iv) mitochondrial reprogramming to refill the TCA cycle through anaplerosis towards anabolic synthesis; (v) increased nucleotide and amino acid synthesis (through enhanced PPP and serine/glycine pathways) for nucleic acid and protein synthesis that support proliferation; (vi) unbalanced NADPH (from enhanced PPP and anaplerotic pathways) needed for lipid synthesis and ROS detoxification, to maintain survival, allow invasiveness and mutations; (vii) production of epigenetic mediators (from mitochondrial reprogramming).

Since glucose excess enhances survival and proliferative phenotypes (De Berardinis \& Chandel 2016, García-Jiménez et al. 2016) and lipids enhance EMT for invasive and metastatic phenotypes (Koundouros \& Poulogiannis 2020), T2D excesses in glucose and lipids might contribute to the phenotypic diversification of advanced tumours. https://erc.bioscientifica com

https://doi.org/10.1530/ERC-21-0092 (c) 2021 Society for Endocrinology Published by Bioscientifica Ltd. Printed in Great Britain 


\section{Metabolism-signalling interactions remodel gene expression}

Metabolic transformation drives genetic and epigenetic modifications (Fig. 1) that favour tumour development (Miranda-Gonçalves et al. 2018). Metabolites and metabolic by-product accumulation, for example, ROS, are increased in many cell types by $\mathrm{T} 2 \mathrm{D}$ following hyperglycaemia (Newsholme et al. 2016) and cause genetic lesions that may drive instability of chromosomes (CIN) or microsatellites (MSI) (Hong 2018). Excess ROS increases the mutation rate of a cell, promoting/maintaining the oncogenic phenotype (Ziech et al. 2011, Hong 2018). In addition, mitochondrial adaptations to supply TCA cycle intermediaries generate oncometabolites such as fumarate, succinate and 2-hydroxyglutarate. Oncometabolites enter the nucleus and regulate the activity of (de)methylases (of DNA and histones) (Yang et al. 2013). Increased methylase and reduced demethylase activity directed by oncometabolites drive uncontrolled gene expression. Epigenome modifications favour genomic instability, mutagenesis and tumour development (Hong 2018). Metabolites able to alter the epigenome in diabetic individuals or cancer cells include: S-adenosyl-L-methionine (SAM) and $\alpha-K G$, involved in methylation or acetyl-CoA and $\mathrm{NAD}^{+}$, involved in acetylation. Some tissues from T2D patients exhibit aberrant methylation and acetylation leading to altered gene expression patterns. Low levels of methyl donors folate and SAM drive improper methylation (Ling \& Rönn 2019) and hyperacetylation of histones at genes related to inflammation (Togliatto et al. 2015) contributes to tumour evolution. Importantly, epigenetic modifications imposed by hyperglycaemia in vascular tissue remain as a 'metabolic memory' after it is controlled. Thus, potential epigenetic changes imposed by T2D in colon epithelium deserve exploration.

Methylation of DNA at CpG islands in gene promoters is associated with transcriptional silencing. Hypermethylation in cancer cells drives the silencing of tumour suppressors (i.e. DNA mismatch repair protein 1, MLH1) or proteasome regulators (i.e. derlin-3, required for degradation of GLUT1) and others. Derlin-3 silencing drives increased GLUT1 and glucose uptake for Warburg effect in cancer cells (Ancey et al. 2018) and would have a bigger impact in T2D patients with deregulated glucose homeostasis. Histone methylation may lead to transcriptional repression or activation, depending on the histone residue and the number of methyl groups incorporated. SAM imbalance drives improper gene methylation in CRC and skeletal muscle of T2D patients (Su et al. 2016). Conversely, demethylation of DNA and histones is controlled by demethylases that use $\alpha-K G$ as co-factor. Demethylases are interfered by oncometabolite such as 2-hydroxyglutarate or fumarate, which are also increased by hyperglycaemia through mitochondrial dysfunction, contributing to improper methylation in T2D patients (Su et al. 2016). Abnormal methylation patterns in different tissues of T2D patients include hypo and hypermethylated genes related to metabolism and inflammation which are very relevant for cancer. Changes in colon epithelium of T2D patients need to be studied.

Acetylation of histones and other proteins is regulated by histone acetyltransferases (HATs) and deacetylases (HDACs). Chromatin acetylation favours an open conformation that allows the recruitment of transcription factors and often correlates with increased gene expression. HATs and HDACs activity are metabolically controlled by the availability of acetyl-CoA and $\mathrm{NAD}^{+}$, as an essential cofactor for HDACs class III (Sirtuins) activity. Metabolic transformation in cancer cells leads to diminished $\mathrm{NAD}^{+} /$ $\mathrm{NADH}$ ratio with the subsequent inhibition of sirtuin activity that may unbalance chromatin acetylation (Miranda-Gonçalves et al. 2018). High glucose increases HAT levels (EP300) and inhibits SIRT1 activity in CRC cells (Chocarro-Calvo et al. 2013, Gutiérrez-Salmerón et al. 2020), unbalancing acetylation. In vivo, tumour development and glycolytic genes upregulation inversely correlate with SIRT6 expression (Sebastián et al. 2012). In CRC, lysine 27 acetylation of histone H3 is increased (Karczmarski et al. 2014). Relevant for the T2D-CRC association, acetylation imbalances have been reported in genes related to inflammation: nuclear factor KB (NFKB) or tumour necrosis factor A (TNFA) in various tissues of T2D patients.

In summary, metabolic reprogramming of cancer cells may follow genetic mutations (altering signalling pathways and/or metabolic enzymes) or mutations may be selected upon systemic metabolism defects that originate oncometabolites to alter the genome/epigenome and lead to CRC.

Wnt, PI3K, RAS-MAPK, TGFB and Hippo signalling (Fig. 2) in CRC cells are subjected to reciprocal crosstalk and are rewired by lipids and high glucose from T2D (Chocarro-Calvo et al. 2013, Santinon et al. 2016). Conversely, mutations that activate these signalling pathways in CRC cells cause metabolic reprogramming and transformation, highlighting the intimate intertwining between metabolism and signalling (GarcíaJiménez et al. 2014, De Berardinis \& Chandel 2016, 
Tiwari et al. 2018). Interestingly, a comparison of human CRC and neighbouring mucosa between diabetic and nondiabetic patients unveiled several cancer-related pathways that were enhanced in non-cancer mucosa of diabetic patients, including Wnt, PI3K/Akt, MAPK, TGFB, Hippo and Notch pathways, suggesting that diabetes promote field cancerization in colonic mucosa (González et al. 2017).

\section{Remodelling CRC cell signalling by hormonal alterations in T2D}

Hormonal imbalances drive the incapacity to control circulating glucose and lipids levels in T2D. Two main axes: insulin/IGFs and leptin/adiponectin stand out in the connection with $\mathrm{CRC}$, although other hormonal alterations may contribute, that is, in glucagon (Yagi et al. 2018) or cortisol (Baritaki et al. 2019). The two arms downstream of insulin/IGF, PI3K and MAPK signalling pathways are altered in T2D and CRC. Crosstalk between PI3K and Wnt signalling through GSK3B inactivation or between Wnt and Hippo through YAP/TAZ and their regulation by metabolites illustrates the importance of their correct wiring for signalling in T2D and CRC
(Santinon et al. 2016, Hwang et al. 2019). Furthermore, leptin/adiponectin imbalances enhance JAK/STAT signalling as inflammatory cytokines do, reinforcing the link with CRC. In this section, we review the possible contribution of T2D-associated defects in the insulin/IGF system, leptin and adiponectin to CRC cell signalling, Fig. 3.

\section{Altered insulin signalling in T2D impacts CRC}

Retarded tumour growth in animals with T1D (Heuson et al. 1972) was an early evidence suggesting that insulin is a growth factor for cancer cells; however, autoimmune defects in T1D may contribute importantly. In vitro, insulin addition to the culture medium increased the anabolic activity and enhanced proliferation rates (Klement \& Kämmerer 2011), reinforcing the concept of insulin as a growth factor for cancer cells; however, the effects of hyperinsulinaemia could not be separated from those of the high glucose in the medium culture. Increased circulating levels of insulin or the related insulin like growth factors (IGF1 and IGF2) were correlated with malignancies (Rowlands et al. 2012) but this included prostate cancers which are inversely associated with both types of diabetes (García-Jiménez et al. 2014,

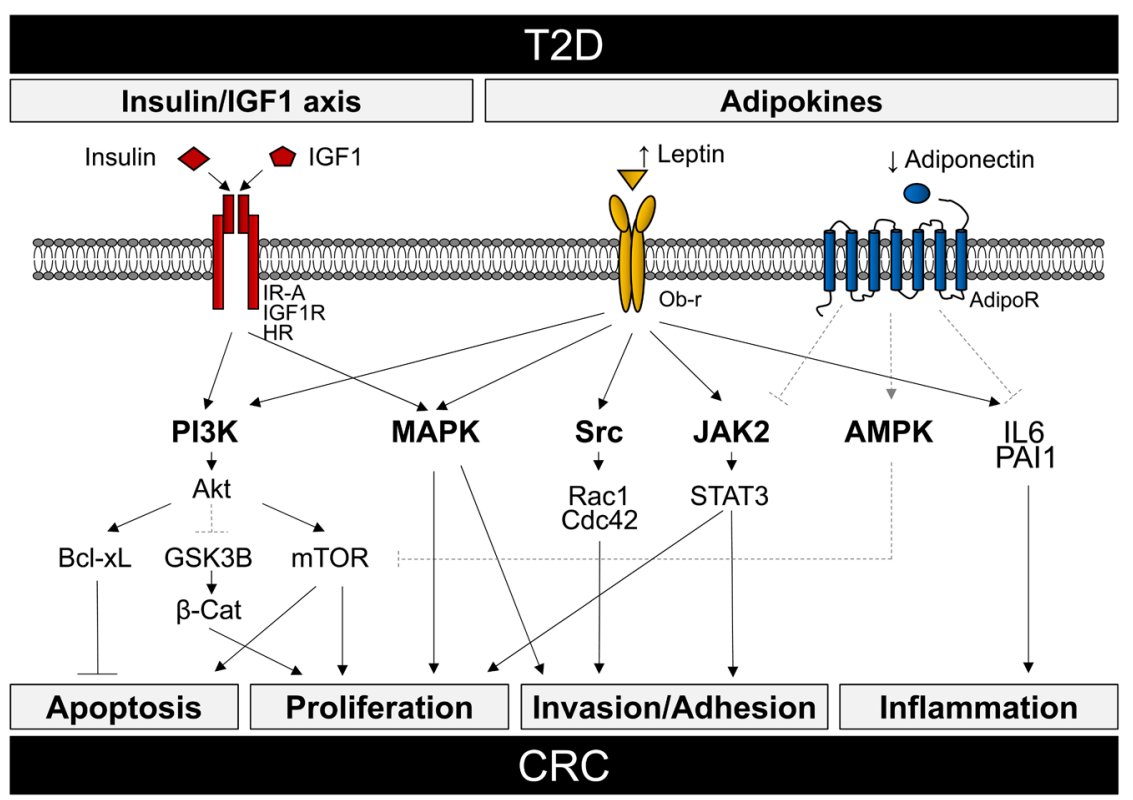

https://erc.bioscientifica.com https://doi.org/10.1530/ERC-21-0092 (c) 2021 Society for Endocrinology Published by Bioscientifica Ltd. Printed in Great Britain
Figure 3

'Hormonal' signalling pathways are implicated in the relationship between T2D and CRC. Insulin/ IGF1 axis signal through IR-A, IGF1R or HR receptors, activating MAPK and PI3K pathways, whose targets enhance apoptosis resistance, invasion and proliferation through $\mathrm{Bcl}-\mathrm{xL}$, mTORC1 and GSK3B inactivation. Leptin binds to Ob-r stimulating proliferation by PI3K/Akt/mTOR, GSK3B and MAPK pathways, inducing migration and invasion through Src/Rac1/Cdc42, JAK2/STAT3 and MAPK pathways. Adiponectin binds AdipoR1/ R2 and antagonizes leptin through LKB1/AMPK that inhibits mTORC1 to block cell growth, suppress proliferation, blocks JAK2/STAT3 signalling by inhibiting cell cycle p21/p27 cyclins and allowing apoptosis. AdipoR1/R2, adiponectin receptors 1/2; AMPK, AMP-activated protein kinase; $\mathrm{Bcl}-\mathrm{xL}$, B-cell lymphoma extra-large; Cdc42, cell division control protein 42 homologue; GSK3B, glycogen synthase kinase-3 B; JAK2, Janus kinase 2; IL6, interleukin 6; LKB1, liver kinase B1; MAPK, mitogen-activated protein kinase; mTORC1, mammalian target of rapamycin, complex 1; Ob-r, leptin receptor; PI3K, phosphatidylinositol 3-kinase; PAl1, plasminogen activator inhibitor type 1; Rac1, Ras-related C3 botulinum toxin substrate 1 ; Src, proto-oncogene tyrosine-protein kinase; STAT3, signal transducer and activator of transcription 3. 
Gutiérrez-Salmerón et al. 2017). The epidemiological link between T2D and CRC was attributed to the compensatory hyper insulinaemic response developed upon insulin resistance or to chronic insulin treatments, although the pattern of association of T1D and T2D to cancers is very different and T1D does not associate to CRC despite the use of insulin in its treatment.

A role for insulin-inducing CRC initiation was inferred when sustained hyper insulinaemic infusion in rats induced the proliferation of normal colorectal epithelial cells and increased the multiplicity of chemically induced aberrant crypts foci (ACF), which are the earliest neoplastic lesions in CRC (Karczewski et al. 2019). Similar results were obtained upon treatment of diabetic mice $(d b d b)$, with commercial insulins (glargine or NPH insulin) (Nagel et al. 2010). In support, other preclinical models of T2D (induced by HFD or genetically in Zucker rats and $K K-A^{y}$ mice) also exhibited increased intestinal adenoma multiplicity (Teraoka et al. 2011, González et al. 2017); however, most T2D models are obese mixing the effects of insulin with those of increased circulating lipids, leptin or inflammatory cytokines.

The influence of insulin on CRC progression was studied by grafting CRC cells in diabetic models. Accelerated growth of MC38 allografts in diabetic mice $(d b d b)$ compared to heterozygotic controls suggested that their sustained high levels of insulin/IGF1 favour CRC progression (Teng et al. 2016). However, high leptin levels in $d b d b$ mice binding to functional leptin receptors in the grafted MC38 cancer cells could also accelerate tumour growth. If insulin accelerates tumour growth, commercial insulin preparations may impact CRC progression. Recombinant human insulin (rI), the X10 analogue and IGF1 effects on tumour progression were compared using HFD obese mice allografted with MC38 CRC cells; IGF1 and X10 but not rI accelerated allografts growth (Hvid et al. 2013). However, none of these treatments altered tumour growth when examined by the same authors 5 years later on a different model, nude mice with diabetes induced with alloxan bearing COLO-205 xenografts (Hvid et al. 2018). Taken together, the results suggest that insulin effects are context-dependent with other hormones (IGF1, IGF2, leptin, etc.), proteins from the IGF axis, metabolites or cytokines defining the effects of insulin on cancer growth.

Mechanistically, insulin excess may promote CRC progression through direct and indirect actions. Indirect insulin effects include favouring IGF1 production and bioavailability. Insulin increases hepatic receptors for growth hormone, the master controller of IGF1 production, and decreases the hepatic production of IGF binding proteins (IGFBPs) to increase IGF1 bioavailability (Stojsavljević et al. 2016). Structural and functional similarities between insulin and IGF1 receptors and their capacity to cross-signal define the insulin/IGF axis. The IGF system includes IGF ligands (IGF1 and IGF2), their membrane receptors, their transporters including high and low affinity, IGFBP 1-6 and IGFBP-rP 1-10, respectively, as well as their degrading enzymes including the metalloproteases MMP7 and MMP9. Many correlations suggest that IGFBPs impact cancer cells in ligand-dependent and -independent manners, but causeeffect evidence is scarce; excellent recent reviews on the subject were included (Yau et al. 2015, Haywood et al. 2019, Jin et al. 2020). Insulin and IGF1 can bind the receptors for insulin (IR), IGF1 (IGF1R) or hybrid IR/IFG1R (HR) receptors. Receptor activation results in signalling through the PI3K-Akt arm, with main downstream effects on survival and metabolism, and through the RasMAPK arm, with mitogenic effects (Stojsavljević et al. 2016, Belfiore et al. 2017), Fig. 3. Both PI3K and MAPK pathways are altered in most CRCs: CMS 2-4 (Fig. 2). Two IR isoforms: IR-A and IR-B have been described; their preferential signalling towards mitogenesis or towards metabolism respectively was attributed to allocation in different raft domains (Belfiore et al. 2017). The IR-A/ IR-B expression ratio is deregulated in metabolic disorders related to diabetes with reduced PI3K-dependent metabolic signalling and excessive PI3K- and MAPK-dependent mitogenic signalling. This may explain accelerated CRC progression in these patients (Stojsavljević et al. 2016). In support, CRC cell lines with high tumourigenic capacity (HT-29, HCT 116 and SW480) show a higher IR-A/IR-B ratio than non-transformed human intestinal epithelial cells (HIEC) (Belfiore et al. 2017). In support, IR-A/IR-B ratio is significantly increased in precancerous adenomas from $\mathrm{Apc}^{\mathrm{Min} /+}$ mice compared with normal tissue and in human CRC carcinoma samples (Vella et al. 2018), suggesting that IR-B could limit intestinal cell proliferation and transformation. Thus, the altered PI3K/MAPK signalling ratio in diabetes favours metabolic reprogramming for proliferation, potentially contributing to CRC initiation. Mutations in key intermediaries (RAS, RAF, APC, etc) are frequent in CRC cells and will prevent potential cross-regulatory modulation further altering homeostasis (Koncina et al. 2020).

High IR-A expression brings to the discussion of another member of this axis IGF2 that binds IR-A (but not IR-B) and signalling preferentially through the ERK arm to enhance mitogenic pathways, making it relevant for cancer. 
IGF2 proliferative effects during development are well known but its function in the adult remains enigmatic, despite its high circulating levels (more than 100-fold those of insulin). IGF2 enhances glucose uptake by muscle and adipose cells but its levels increase with obesity, emerging as a potential link between obesity and diabetes. Loss of imprinting and high IGF2 expression correlate with a history of cancers which are oppositely associated to T2D, including CRC and prostate cancer. IGF2 is part of a complex transcriptional unit, important for metabolism control, that includes RNA binding proteins and several epigenetic regulators (lncRNAs and miRNAs) that control methylation, acetylation, cell cycle and IRs expression. Understanding the integrated regulation of the IGF2 system should help to understand the T2D-CRC association. Excellent in-depth recent reviews of the subject are Baritaki et al. (2019), Holly et al. (2019) and Yagi et al. (2018).

The PI3K/MAPK signalling imbalance in diabetes and CRC might respond to altered IR-A and IGF1R expression. Overexpression of IRs and IGF1R by cancer cells supports the insulin and IGFs role as drivers of cancer cell growth. However, these receptors are overexpressed in most solid and hematopoietic tumours, not specifically in cancers associated with diabetes, suggesting that the T2D-CRC association is supported by additional factors (Belfiore et al. 2017). Stable in vitro overexpression of IGF1R in HCT 116 cells (HCT 116/IGF1R) enhanced invasion and apoptosis resistance through the Akt/Bcl-xL pathway (Sekharam et al. 2003) leading to an aggressive phenotype. Consistently, IGF1R knockdown in HT-29 or SW620 CRC cells drove reduced PI3K/Akt signalling towards GSK3B inactivation, subsequently promoting $\beta$-catenin degradation and, therefore, a reduced expression of Wnt/ $\beta$-catenin-dependent genes (Zhang et al. 2015) to decrease proliferation (Fig. 3). Consistent with in vitro data, in nude mice xenografts of HCT 116/IGF1R cells led to highly invasive tumours and distant metastases, whereas xenografts of HT-29 cells expressing a truncated, signalling-defective form of IFG1R (IGF1R DN) significantly decreased tumour growth compared with HT-29 parental cells (Vigneri et al. 2015). Despite the IR and IGF1R abundance in human HCT 116 CRC cells, hybrid IR-A/IGF1R (HR-A) receptor levels are low and cannot mediate survival and proliferation (Belfiore et al. 2017). Whether this is due to particularities of the lipid membrane composition is unknown. Human CRC samples exhibit higher IR-A than IGF1R expression, making HR-A unlikely and highlighting potential IR-A/IGF2 signalling.
Downstream of IR and IGF1R, the IR substrates (IRS 1-4) scaffold the signal primarily towards PI3K. IRS malfunction has been well studied in diabetes (Lavin et al. 2016) and appears critical in CRC aggressiveness (Day et al. 2013). IRS2 overexpression in CRC cells SW480 activates the oncogenic branches of PI3K/Akt signalling, reducing cell adhesion and promoting cell invasion in vitro (Fig. 3). Consistently, IRS1/2 expression positively correlates with CRC progression and metastasis in human samples (Stojsavljević et al. 2016). Some IRS1 and IRS2 polymorphisms have been independently associated with diabetes and with increased CRC risk, but how the identified variants affect protein levels and modulate IR/ IGF1R signalling in CRC tumourigenesis remain unclear (Vigneri et al. 2015). Further studies are necessary to clarify the role of these mutations in CRC progression.

Thus, aberrant insulin/IGF signalling may favour CRC initiation and progression, but most T2D animal models are obese implying alternative metabolic and/or hormonal factors that exert their own effects and modulate those of the insulin/IGF system. This is important because obesity is the most common cause of insulin resistance and contributing factor for T2D development and because obesity per se is associated with CRC.

\section{Unbalanced leptin/adiponectin in T2D impacts CRC}

Few obese people become diabetic but most T2D patients are obese. Excess adipose tissue contributes to the T2DCRC link with adipokine (leptin and adiponectin) and cytokine imbalances, the latter was analysed in GutiérrezSalmerón et al. (2021). Obese and T2D patients exhibit increased leptin/adiponectin ratios that correlate with tumour TNM stages in CRC (Uyar \& Sanlier 2019). In vitro, leptin stimulates CRC cell proliferation through the modulation of PI3K/Akt/mTOR, GSK3B and MAPK pathways, Fig. 3 (Aparicio et al. 2005, Ghasemi et al. 2019); leptin exerts anti-apoptotic effects via PI3K/Akt, JAK2/ STAT3 and JNK pathways (Nikolaou et al. 2019); leptin induces migration and invasion in CRC cells through the Src/Rac1/Cdc42, MAPK and PKCD pathways (Fig. 3) (Ghasemi et al. 2019). Despite these in vitro evidences, sustained, intense hyper-leptinaemia did not promote the growth of HT-29 CRC cell xenografts in nude mice, neither enhanced development, growth or metastasis of adenomas in $\mathrm{Apc}^{\mathrm{Min} /+}$ mice CRC models (Aparicio et al. 2005). Perhaps other factors (unidentified yet) modify the effects of leptin and may reconcile in vitro and in vivo evidence. 
To understand the role of leptin in CRC initiation, obese mice (with HFD) were treated with azoxymethane (AOM) (triple cycle) to induce ACFs formation. Leptin signalling did not promote or interfere with normal colon epithelial cell proliferation and did not promote premalignant lesions after two AOM cycles (Endo et al. 2011). However, after the third AOM cycle (which is still early tumourigenesis), increased serum leptin levels correlated with increased ACF number. Arguably, these effects could be alternatively attributed to increased circulating lipids, inflammatory cytokines, and decreased adiponectin. However, alternative models of diabetesinduced through mutations in the leptin gene (obob mice) or the leptin receptor gene ( $d b d b$ mice) support a role for leptin in early CRC progression. Despite severe obesity, lack of leptin signalling in these models correlated with dramatically reduced number and growth of AOMinduced ACFs compared to their heterozygotic controls (Endo et al. 2011). Interestingly, the growth of tumours was slower in mice without leptin (obob) than in mice with mutant receptors $(d b d b)$ suggesting complex signalling outputs from leptin and its receptors (Endo et al. 2011).

By contrast with leptin, the levels of circulating adiponectin (APN), another adipose tissue secreted hormone, are diminished in obesity and T2D as well as in CRC. Adiponectin exhibits opposite effects to leptin, with anti-angiogenic, anti-proliferative and anti-inflammatory properties that may interfere with CRC-development. In vitro, adiponectin signalling through LKB1/AMPK inhibits mTORC1, suppressing proliferation and colony formation of human CRC cells (Fig. 3). Adiponectin blocks JAK/ STAT3 signalling, inhibiting cell cycle progression through p21/p27 cyclins and allowing apoptosis (Parida et al. 2019). In vivo, adiponectin significantly decreases polyp formation in CRC mouse models $\left(\mathrm{ApC}^{\mathrm{Min} /+}\right)$ and suppresses the growth of MC38 xenografts in HFD-fed mice (Otani et al. 2017). The timing for adiponectin experiments was comparable to leptin treatments that induced no changes in tumour growth (Aparicio et al. 2005). In contrast, after diabetes induction through HFD, mice models lacking adiponectin $\left(\mathrm{Apn}^{-/-}\right)$were more prone to CRC development through AOM treatment (Parida et al. 2019) or chronic inflammation (Otani et al. 2017). Consistent with previous results, AdipoRon, a synthetic adiponectin analogue diminished the proliferation in early CRC stages and prevented CRC related to T2D (Nikolaou et al. 2019). Notably, AdipoRon also improved insulin resistance and glucose tolerance in obese, diabetic mouse models suggesting that its effects may be mediated by insulin, glucose or other factors. However, constitutively elevated levels of circulating adiponectin in transgenic (AdTg) mice did not confer protection against AOM-induced CRC (Otani et al. 2017) suggesting that as for insulin and leptin, adiponectin effects might be modulated or indirect and highlighting the importance of combining models.

Adding to the antagonistic leptin/adiponectin secretion defects in $\mathrm{T} 2 \mathrm{D}$ and the anti-inflammatory effects of adiponectin, increased leptin levels correlate with increased proinflammatory cytokines (IL6, PAI1), suggesting a possible reciprocal regulation or cooperation. In support, high leptin and pro-inflammatory cytokines levels correlate positively with CRC development. The inverse correlation between soluble leptin receptor and anti-inflammatory cytokine levels along with CRC development might also support this cooperation (Karczewski et al. 2019).

Thus, the molecular mechanisms by which insulin/IGF1 and leptin/adiponectin contribute to the development and/or progression of CRC in T2D patients appear to be intimately linked to metabolic and inflammatory abnormalities. Future studies should elucidate the relationship between individual factors and how do they contribute to CRC progression.

\section{Models to study the association between CRC and T2D}

In vitro models have helped to study multiple genetic mutations and are adequate to study mechanisms in a controlled way. However, although cell lines can be cultured easily, the cellular heterogeneity of tumours is missing. In this respect, organoids model better the structure-function of tissues but remain very costly to culture. The frailty of in vitro models lies in their inadequacy to study tumour-environment interactions, making necessary the use of in vivo models which are often difficult to interpret.

In vivo models allow the study of interactions between different tissues and organs. Non-mammalian experimental organisms with a short life cycle (Zebrafish, C. elegans and Drosophila) share similar biochemistry but exhibit important physiological differences with humans. Among mammalians, rodent models are preferred because of physiological similarity to humans, the wealth of research that supports their study $(60 \%$ preclinical models are in Mus musculus) (Day et al. 2015, Kleinert et al. 2018) and cost-effectiveness. A variety of mouse models to study diabetes and cancer initiation and progression have been developed. The criteria to 
select the best fit for a particular study includes strain, sex and age-related disease inducers, as these factors heavily influence the results. Although murine pancreatic islet architecture is different from humans, mice models mimic quite well diabetes characteristics (Kleinert et al. 2018). Here, we summarize that most of the T2D might be modelled in mice by induction with exogenous agents or through genetic mutations. Feeding ad libitum with diets enriched in fat (45-60\%), sugar (5-30\%) and/or sodium slowly but quite faithfully in models of human T2D in mice. Impaired leptin signalling, chronic inflammation, non-alcoholic fatty liver or artery diseases were studied in these models. This slow T2D model is optimal to study tumour initiation. T2D appearance can be accelerated by combining HFD with low-doses of streptozotocin (a glucose analogue that damages DNA), to which $\beta$-pancreatic cells are especially sensitive due to the high exhibition of GLUT2 transporters. Streptozotocin alone in higher doses destroys $\beta$-cells in T1D models (Heydemann 2016).

\section{T2D models}

Genetically modified mice models with diabetic phenotype have been developed mainly in Balbc and C57BL background, with the latest more widely used due to Balbc mice resistance to develop obesity. Amongst C57BL, the strain C57BLKS is more widely used due to its increased susceptibility to T2D induction. Monogenic models are easier to obtain, and two models based on the disruption of leptin signalling to impair satiety result in obesity-driven diabetes. First, obob mice have a single autosomal recessive mutation on the gene encoding leptin, resulting in non-functional leptin. Secondly, $d b d b$ mice have a single autosomal recessive mutation on the leptin receptor gene: a 106-nucleotide insertion that prematurely terminates the intracellular domain, leading to impaired signalling. Interestingly, obob mice present a milder T2D phenotype compared to $d b d b$ mice (King \& Austin 2017), highlighting the importance of signalling by the intracellular domain of the leptin receptor to prevent diabetes. Although in most human cases, T2D develops slowly associated to metabolic defects, research efforts directed to clarify possible genetic defects associated to T2D suggest that polygenic models may better reflect the genetic variety of human T2D. The most widely used polygenic mouse models are $K K-A y$, New Zealand Obese (Pctp and Cox7a2l mutations) and TALLYHO/Ing (Tanidd1, Tanidd2, Tanidd3, Tabw2, and Tafat mutations). Defects on leptin transport across the blood brain barrier render the New Zealand more obese than KK-Ay and TALLYHO/Jng, although they all develop insulin resistance and mature-onset hyperglycaemia except for the female of TALLYHO/Jng (King \& Austin 2017, Kleinert et al. 2018).

\section{CRC models}

Perhaps, the most basic way to study the influence of the environment on cancer growth is the inoculation/ grafting of cancer cells in mice. Human cancer cells must be inoculated in immunosuppressed (nude) mice and exclude the possibility to study the contribution of the immune response. This is surpassed by inoculating murine cancer cells of the same strain (maximizing genetic homogeneity) allowing studies of the immune contribution. In addition to the type of cancer cells to be used, the location where cancer cells are introduced in the mice is very important and will be defined by the question that is addressed. Subcutaneous grafting is quick and simple and allows to follow and measure growth and structure rapidly with a calliper. Intraperitoneal injection of tumour cells or injection through the tail vein might help to study cancer cell resistance to the immune system (Day et al. 2015) and the capacity to invade. However, to study the complex interactions of CRC cancer cells with their microenvironment, an orthotopic inoculation in the gastrointestinal tract of the same strain must be used.

CRC can be induced by environmental/ chemical compounds or using genetic models. The main chemical compounds used to induce CRC are 1,2-dDimethylhydrazine (DMH) and its metabolite AOM. These procarcinogen drugs enhance ROS production causing DNA damage in the liver, lungs and colon. Although DMH induces more advanced tumours, AOM is usually preferred because of its reproducibility, simple application, good stability and low price (De Robertis et al. 2011). To study CRC progression, AOM tumourigenesis is enhanced by general inflammation-induced with dextran sulphate sodium (DSS).

Genetic models of CRC were developed based on the most frequent mutations in human CRC. The most frequently used monogenic models bear mutations in Apc (downstream of Wnt) Fig. 2. Monogenic mutations in p53 and Kras (downstream of tyrosine kinase receptors) do not induce CRC but the combination with others potentiate its tumourigenicity. Faithful models require the combination of several mutations or combined mutation(s) with an exogenous agent (De-Souza \& Costa-Casagrande 2018). Since mutations in APC or its downstream signalling 
pathway appear in 70-80\% of human sporadic CRCs, the most popular mouse model bears a particular mutation (Min) in the Apc gene; Apc ${ }^{\mathrm{Min}}$ mouse form polyps and develop CRC of the CMS2 subtype (Fig. 2) (Stastna et al. 2019). An inconvenience of this model is that, unlike human $\mathrm{CRC}$, the majority of mice polyps appear in the small intestine, and mice die early by day 120 (De-Souza \& Costa-Casagrande 2018, Ren et al. 2019).

At present, there are scarce publications with mice that combine both CRC and T2D. The most widespread models are s.c. allografts of CRC cells in the right flank of diabetic mice (diabetes originated genetically) with a general C57BL genetic background. As such, $d b d b$ mice have been subcutaneously allografted with CRC cells of their background (MC38) to study the mechanisms by which insulin and IGF1 enhance cancer cell proliferation (Teng et al. 2016). Alternatively, environmentally induced T2D through HFD in mice subsequently allografted with CRC cells (CMT93 for C57BL/6 background) were used to evaluate the role of glucagon in the proliferation of CRC cells (Yagi et al. 2018). The choice of different models to study the effects of insulin or glucagon is a barrier to compare results.

Since obesity and T2D might contribute to CRC with complementary contributors, the mouse strain Balbc, that is refractory to HFD-induced obesity, was chosen to study the influence of T2D in CRC development separately from obesity. In this model, HFD stimulated angiogenesis, tumour growth and lung metastases of allografted CRC cells from the same genetic background, CT26 (Park et al. 2012), supporting the notion that T2D contributes with factors independent of obesity to CRC progression, although the identity of such factors remains elusive.

Few researchers have combined models of in situ CRC with diabetes. A very interesting work from Ito's group compared the susceptibility to develop CRC using AOM in females from different genetic backgrounds related to obesity/diabetes, such as $K K-A y$ (obese and T2D), KK (only obese), control ICR (similar weight to $K K-A y$ at young ages and with CRC induced by AOM), control C57BL/6J (non T2D and non-obese). Combined obesity and T2D in $K K-A y$ mice were the most susceptible to AOM induction of CRC, supporting the idea of cooperative factors from obesity and T2D (Ito et al. 2013). Alternatively, AOM induction and growth of CRC have been compared in mice where diabetes was induced with HFD or genetically $(d b d b$ or $o b o b)$. These experiments demonstrated that HFD accelerates CRC growth only in mice with intact leptin signalling but not in $o b o b$ or $d b d b$ mice (Endo et al. 2011); increased epithelial expression of the leptin receptor and its signalling through JAK/STATs mediated HFD effects.

Thus, the choice of mouse models with T2D and CRC combining genetics and/or chemical inducers must be based on the question to answer regarding the interaction of both diseases. Research is hampered by the difficulties to obtain the models and the complicated interactions between specific contributing factors.

\section{Conclusions and future perspectives}

Metabolic and hormonal defects imposed by diabetes favour the metabolic transformation and alter signalling, geneticandepigeneticstosupport thetumourdevelopment. Metabolic environment might select genetic mutations and genetic mutations induce metabolic transformation, Fig. 4. Not only tumour cells also their micro- and

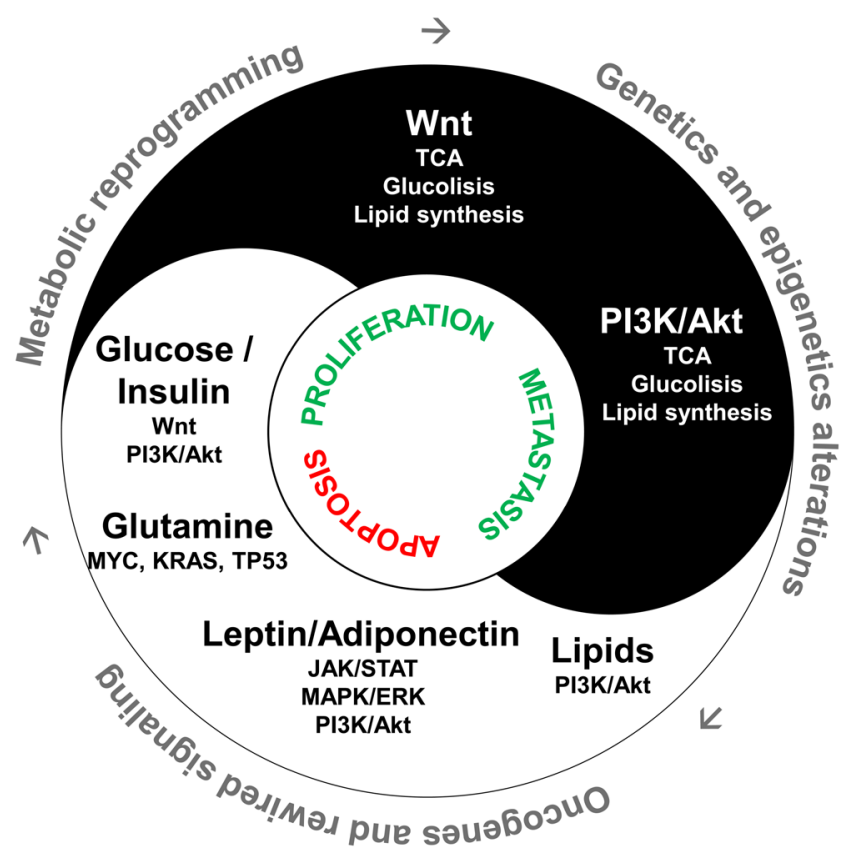

Figure 4

Metabolism and hormones in T2D facilitate metabolic reprogramming, rewired signalling and genetic and epigenetic changes to favour cancer cell transformation. A positive feedback loop is created through metabolic reprogramming, promoting epigenetic modifications of chromatin and proteins and genetic alterations that favour oncogenes activity by rewiring signalling and driving the expression of metabolism-associated genes that feedback towards a metabolic transformation that facilitates colorectal cancer development and progression. Highlighted are the main metabolites, hormones and signalling pathways that enhance proliferation and metastasis (green) while inhibiting apoptosis (red). Akt, protein kinase B; MAPK, mitogen-activated protein kinase; PI3K, phosphatidylinositol 3-kinase; JAK, Janus kinase; STAT, signal transducer and activator of transcription; TCA, tricarboxylic acid cycle. 


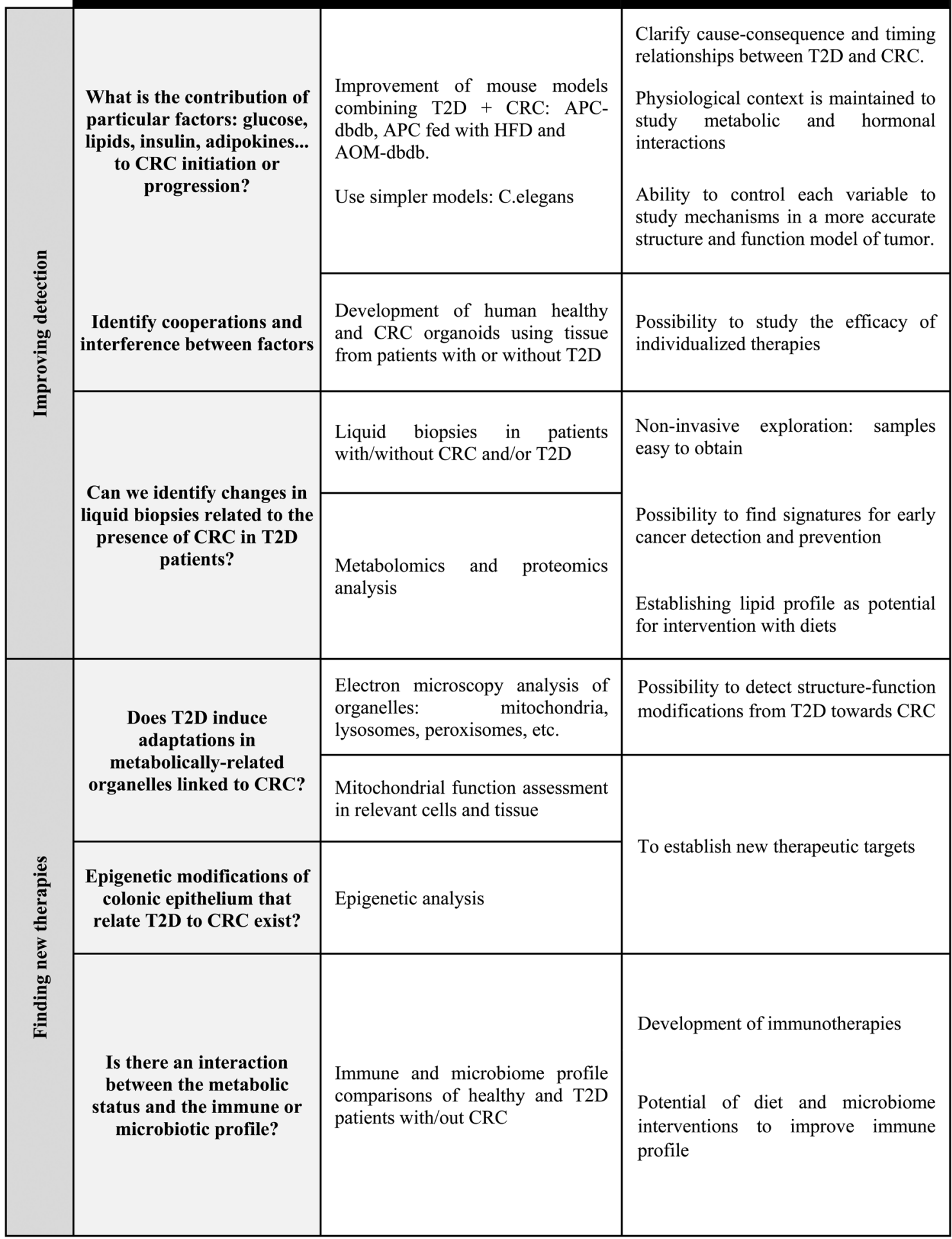

Figure 5

Outstanding questions and future perspectives. Summary of the aspects that must be addressed to increase the understanding of the relationship between T2D and CRC in order to improve its detection and develop new therapies. AOM, azoxymethane; APC, adenomatous polyposis coli; CRC, colorectal cancer; HFD, high fat diet; T2D, type 2 diabetes. 
macro-environment will be impacted by the systemic metabolic and hormonal defects of diabetes.

Given the increased incidence of CRC at younger ages, the prevention, detection and therapies must be optimized. Figure 5 summarizes outstanding questions and the more promising approaches to improve them. Organoids and liquid biopsies combined with -omic are especially promising.

It is unknown whether CRC develops after diabetes or diabetes may appear as a consequence of the CRC, whether CRCs are milder in the diabetic population or more aggressive or if CRCs are detected earlier in T2D patients due to their closer medical control. Given the number of CRCs developed in T2D patients, specific guidelines for CRC screening among diabetic patients can reduce $\mathrm{CRC}$ incidence.

\section{Declaration of interest}

The authors declare that there is no conflict of interest that could be perceived as prejudicing the impartiality of this review.

\section{Funding}

The financial support of the Spanish government (Grant Nos. AEI, Mineco/FEDER SAF2016-79837-R and PID2019-110998RB-I00) is gratefully acknowledged. A C-C was supported by Comunidad de Madrid: Ayudas Atracción de Talento (2017-T1/BMD-5334). S R L was supported by Comunidad de Madrid/FEDER-PEJD-2017-POST/BMD-3906.

\section{References}

Akella NM, Ciraku L \& Reginato MJ 2019 Fueling the fire: emerging role of the hexosamine biosynthetic pathway in cancer. BMC Biology 17 52. (https://doi.org/10.1186/s12915-019-0671-3)

Ancey PB, Contat C \& Meylan E 2018 Glucose transporters in cancer from tumor cells to the tumor microenvironment. FEBS Journal $\mathbf{2 8 5}$ 2926-2943. (https://doi.org/10.1111/febs.14577)

Aparicio T, Kotelevets L, Tsocas A, Laigneau JP, Sobhani I, Chastre E \& Lehy T 2005 Leptin stimulates the proliferation of human colon cancer cells in vitro but does not promote the growth of colon cancer xenografts in nude mice or intestinal tumorigenesis in ApcMin/+ mice. Gut 54 1136-1145. (https://doi.org/10.1136/ gut.2004.060533)

Baritaki S, de Bree E, Chatzaki E \& Pothoulakis C 2019 Chronic stress, inflammation, and colon cancer: a CRH system-driven molecular crosstalk. Journal of Clinical Medicine 8 1669. (https://doi. org/10.3390/jcm8101669)

Belfiore A, Malaguarnera R, Vella V, Lawrence MC, Sciacca L, Frasca F, Morrione A \& Vigneri R 2017 Insulin receptor isoforms in physiology and disease: an updated view. Endocrine Reviews $\mathbf{3 8}$ 379-431. (https://doi.org/10.1210/er.2017-00073)

Beloribi-Djefaflia S, Vasseur S \& Guillaumond F 2016 Lipid metabolic reprogramming in cancer cells. Oncogenesis 5 e189-e189. (https://doi. org/10.1038/oncsis.2015.49)
Berridge MJ 2017 Vitamin D deficiency and diabetes. Biochemical Journal 474 1321-1332. (https://doi.org/10.1042/BCJ20170042)

Chocarro-Calvo A, García-Martínez JM, Ardila-González S, De la Vieja A \& García-Jiménez C 2013 Glucose-induced $\beta$-catenin acetylation enhances Wnt signaling in cancer. Molecular Cell 49 474-486. (https://doi.org/10.1016/j.molcel.2012.11.022)

da Cunha BR, Domingos C, Buzzo Stefanini ACB, Henrique T, Polachini GM, Castelo-Branco P \& Tajara EH 2019 Cellular interactions in the tumor microenvironment: the role of secretome. Journal of Cancer 10 4574-4587. (https://doi.org/10.7150/jca.21780)

Dai W \& Jiang L 2019 Dysregulated mitochondrial dynamics and metabolism in obesity, diabetes, and cancer. Frontiers in Endocrinology 10 570. (https://doi.org/10.3389/fendo.2019.00570)

Day E, Poulogiannis G, Mccaughan F, Mulholland S, Arends MJ, Ibrahim AEK \& Dear PH 2013 IRS2 is a candidate driver oncogene on 13q34 in colorectal cancer. International Journal of Experimental Pathology 94 203-211. (https://doi.org/10.1111/iep.12021)

Day CP, Merlino G \& Van Dyke T 2015 Preclinical mouse cancer models: a maze of opportunities and challenges. Cell 163 39-53. (https://doi. org/10.1016/j.cell.2015.08.068)

De Berardinis RJ \& Chandel NS 2016 Fundamentals of cancer metabolism. Science Advances 2 e1600200. (https://doi.org/10.1126/ sciadv.1600200)

De Robertis M, Massi E, Poeta ML, Carotti S, Morini S, Cecchetelli L, Signori E \& Fazio VM 2011 The AOM/DSS murine model for the study of colon carcinogenesis: from pathways to diagnosis and therapy studies. Journal of Carcinogenesis 10 9. (https://doi. org/10.4103/1477-3163.78279)

Dekker E, Tanis PJ, Vleugels JLA, Kasi PM \& Wallace MB 2019 Colorectal cancer. Lancet 394 1467-1480. (https://doi.org/10.1016/S01406736(19)32319-0)

De-Souza ASC \& Costa-Casagrande TA 2018 Animal models for colorectal cancer. Arquivos Brasileiros de Cirurgia Digestiva 31 e1369. (https://doi.org/10.1590/0102-672020180001e1369)

Endo H, Hosono K, Uchiyama T, Sakai E, Sugiyama M, Takahashi H, Nakajima N, Wada K, Takeda K, Nakagama H, et al. 2011 Leptin acts as a growth factor for colorectal tumours at stages subsequent to tumour initiation in murine colon carcinogenesis. Gut $\mathbf{6 0}$ 1363-1371. (https://doi.org/10.1136/gut.2010.235754)

Ferrer-Mayorga G, Larriba MJ, Crespo P \& Muñoz A 2019 Mechanisms of action of vitamin D in colon cancer. Journal of Steroid Biochemistry and Molecular Biology 185 1-6. (https://doi.org/10.1016/j. jsbmb.2018.07.002)

García-Jiménez C, García-Martínez JM, Chocarro-Calvo A \& De la Vieja A 2014 A new link between diabetes and cancer: enhanced $\mathrm{WNT} / \beta$-catenin signaling by high glucose. Journal of Molecular Endocrinology 52 R51-R66. (https://doi.org/10.1530/JME-13-0152)

García-Jiménez C, Gutiérrez-Salmerón M, Chocarro-Calvo A, GarcíaMartinez JM, Castaño A \& De La Vieja A 2016 From obesity to diabetes and cancer: epidemiological links and role of therapies. British Journal of Cancer 114 716-722. (https://doi.org/10.1038/ bjc.2016.37)

Ghasemi A, Saeidi J, Azimi-Nejad M \& Hashemy SI 2019 Leptininduced signaling pathways in cancer cell migration and invasion. Cellular Oncology 42 243-260. (https://doi.org/10.1007/s13402-019. 00428-0)

González N, Prieto I, del Puerto-Nevado L, Portal-Nuñez S, Ardura JA, Corton M, Fernández-Fernández B, Aguilera O, Gomez-Guerrero C, Mas S, et al. 20172017 Update on the relationship between diabetes and colorectal cancer: epidemiology, potential molecular mechanisms and therapeutic implications. Oncotarget 8 18456-18485. (https://doi.org/10.18632/oncotarget.14472)

Guinney J, Dienstmann R, Wang X, De Reyniès A, Schlicker A, Soneson C, Marisa L, Roepman P, Nyamundanda G, Angelino P, et al. 2015 The consensus molecular subtypes of colorectal cancer. Nature Medicine 21 1350-1356. (https://doi.org/10.1038/nm.3967) 
Gutiérrez-Salmerón M, Chocarro-Calvo A, García-Martínez JM, de la Vieja A \& García-Jiménez C 2017 Epidemiological bases and molecular mechanisms linking obesity, diabetes, and cancer. Endocrinologia, Diabetes y Nutricion 64 109-117. (https://doi. org/10.1016/j.endinu.2016.10.005)

Gutiérrez-Salmerón M, García-Martínez JM, Martínez-Useros J, Fernández-Aceñero MJ, Viollet B, Olivier S, Chauan J, Lucena SR, De la Vieja A, Goding CR, et al. 2020 Paradoxical activation of AMPK by glucose drives selective EP300 activity in colorectal cancer. PLoS Biology 18 e3000732. (https://doi.org/10.1371/journal. pbio.3000732)

Gutiérrez-Salmerón M, Lucena SR, Chocarro-Calvo A, GarciaMartinez JM, Martín Orozco RM \& Goding CR 2021 Remodelling of colorectal cancer cell signalling by microbiota and immunity in diabetes. Endocrine-Related Cancer 28 R173-R190. (https://doi. org/10.1530/ERC-20-0315)

Haywood NJ, Slater TA, Matthews CJ \& Wheatcroft SB 2019 The insulin like growth factor and binding protein family: novel therapeutic targets in obesity and diabetes. Molecular Metabolism 19 86-96. (https://doi.org/10.1016/j.molmet.2018.10.008)

Heuson JC, Legros N \& Heimann R 1972 Influence of Insulin Administration on Growth of the 7,12-dimethylbenz(a)anthraceneinduced mammary carcinoma in intact, oophorectomized, and hypophysectomized rats. Cancer Research 32 233-238.

Heydemann A 2016 An overview of murine high fat diet as a model for type 2 diabetes mellitus. Journal of Diabetes Research 20162902351. (https://doi.org/10.1155/2016/2902351)

Holly JMP, Biernacka K \& Perks CM 2019 The neglected insulin: IGF-II, a metabolic regulator with implications for diabetes, obesity, and cancer. Cells 8 1207-1239. (https://doi.org/10.3390/cells8101207)

Hong SN 2018 Genetic and epigenetic alterations of colorectal cancer. Intestinal Research 16 327-337. (https://doi.org/10.5217/ ir.2018.16.3.327)

Hvid H, Blouin MJ, Birman E, Damgaard J, Poulsen F, Fels JJ, Fledelius C, Hansen BF \& Pollak M 2013 Treatment with insulin analog x10 and IGF-1 increases growth of colon cancer allografts. PLOS ONE $\mathbf{8}$ e79710. (https://doi.org/10.1371/journal.pone.0079710)

Hvid H, Jørgensen MS, Blume N, Slaaby R, Lützen A \& Hansen BF 2018 Activation of insulin receptors and IGF-1 receptors in COLO-205 colon cancer xenografts by insulin and insulin analogue $\mathrm{x} 10$ does not enhance growth under normo- or hypoglycaemic conditions. Diabetologia 61 2447-2457. (https://doi.org/10.1007/s00125-0184684-1)

Hwang JH, Kim AR, Kim KM, Il Park J, Oh HT, Moon SA, Byun MR, Jeong H, Kim HK, Yaffe MB, et al. 2019 TAZ couples Hippo/Wnt signalling and insulin sensitivity through Irs1 expression. Nature Communications 10 421. (https://doi.org/10.1038/s41467-019-08287-x)

Ito K, Ishigamori R, Mutoh M, Ohta T, Imai T \& Takahashi M 2013 Ay allele promotes azoxymethane-induced colorectal carcinogenesis by macrophage migration in hyperlipidemic/diabetic KK mice. Cancer Science 104 835-843. (https://doi.org/10.1111/cas.12162)

Jiang X, Peng M, Chen S, Wu S \& Zhang W 2019 Vitamin D deficiency is associated with dyslipidemia: a cross-sectional study in 3788 subjects. Current Medical Research and Opinion 35 1059-1063. (https://doi.org/10.1080/03007995.2018.1552849)

Jin L, Shen F, Weinfeld M \& Sergi C 2020 Insulin growth factor binding protein 7 (IGFBP7)-related cancer and IGFBP3 and IGFBP7 crosstalk. Frontiers in Oncology 10 727. (https://doi.org/10.3389/ fonc.2020.00727)

Karczewski J, Begier-Krasińska B, Staszewski R, Popławska E, GulczynskaElhadi K \& Dobrowolska A 2019 Obesity and the risk of gastrointestinal cancers. Digestive Diseases and Sciences 64 2740-2749. (https://doi.org/10.1007/s10620-019-05603-9)

Karczmarski J, Rubel T, Paziewska A, Mikula M, Bujko M, Kober P, Dadlez M \& Ostrowski J 2014 Histone H3 lysine 27 acetylation is altered in colon cancer. Clinical Proteomics 11 24. (https://doi. org/10.1186/1559-0275-11-24)

King A \& Austin A 2017 Chapter 10: Animal models of type 1 and type 2 diabetes mellitus. In Animal Models for the Study of Human Disease. Amsterdam, Netherlands: Elsevier Inc. (https://doi.org/10.1016/B9780-12-809468-6.00010-3)

Kleinert M, Clemmensen C, Hofmann SM, Moore MC, Renner S, Woods SC, Huypens P, Beckers J, De Angelis MH, Schürmann A, et al. 2018 Animal models of obesity and diabetes mellitus. Nature Reviews: Endocrinology 14 140-162. (https://doi.org/10.1038/nrendo.2017.161)

Klement RJ \& Kämmerer U 2011 Is there a role for carbohydrate restriction in the treatment and prevention of cancer? Nutrition and Metabolism 8 75. (https://doi.org/10.1186/1743-7075-8-75)

Koncina E, Haan S, Rauh S \& Letellier E 2020 Prognostic and predictive molecular biomarkers for colorectal cancer: updates and challenges. Cancers 12 319. (https://doi.org/10.3390/cancers12020319)

Koo JH \& Guan KL 2018 Interplay between YAP/TAZ and metabolism. Cell Metabolism 28 196-206. (https://doi.org/10.1016/j. cmet.2018.07.010)

Koundouros N \& Poulogiannis G 2020 Reprogramming of fatty acid metabolism in cancer. British Journal of Cancer 122 4-22. (https://doi. org/10.1038/s41416-019-0650-z)

Lavin DP, White MF \& Brazil DP 2016 IRS proteins and diabetic complications. Diabetologia 59 2280-2291. (https://doi.org/10.1007/ s00125-016-4072-7)

Lee JE, Li H, Chan AT, Hollis BW, Lee IM, Stampfer MJ, Wu K, Giovannucci E \& Ma J 2011 Circulating levels of vitamin D and colon and rectal cancer: the Physicians' Health Study and a metaanalysis of prospective studies. Cancer Prevention Research 4 735-743. (https://doi.org/10.1158/1940-6207.CAPR-10-0289)

Li B \& Simon MC 2013 Molecular pathways: targeting MYC-induced metabolic reprogramming and oncogenic stress in cancer. Clinical Cancer Research 19 5835-5841. (https://doi.org/10.1158/1078-0432. CCR-12-3629)

Ling C \& Rönn T 2019 Epigenetics in human obesity and Type 2 diabetes. Cell Metabolism 29 1028-1044. (https://doi.org/10.1016/j. cmet.2019.03.009)

Miranda-Gonçalves V, Lameirinhas A, Henrique R \& Jerónimo C 2018 Metabolism and epigenetic interplay in cancer: regulation and putative therapeutic targets. Frontiers in Genetics 9 427. (https://doi. org/10.3389/fgene.2018.00427)

Mouillet-Richard S \& Laurent-Puig P 2020 YAP/TAZ signalling in colorectal cancer: lessons from consensus molecular subtypes. Cancers 12 1-18. (https://doi.org/10.3390/cancers12113160)

Nagel JM, Staffa J, Renner-Müller I, Horst D, Vogeser M, Langkamp M, Hoeflich A, Göke B, Kolligs FT \& Mantzoros CS 2010 Insulin glargine and NPH Insulin increase to a similar degree epithelial cell proliferation and aberrant crypt foci formation in colons of diabetic mice. Hormones and Cancer 1 320-330. (https://doi.org/10.1007/ s12672-010-0020-z)

Newsholme P, Cruzat VF, Keane KN, Carlessi R \& de Bittencourt PI 2016 Molecular mechanisms of ROS production and oxidative stress in diabetes. Biochemical Journal 473 4527-4550. (https://doi. org/10.1042/BCJ20160503C)

Nikolaou S, Qiu S, Fiorentino F, Rasheed S, Tekkis P \& Kontovounisios C 2019 The prognostic and therapeutic role of hormones in colorectal cancer: a review. Molecular Biology Reports 46 1477-1486. (https://doi. org/10.1007/s11033-018-4528-6)

Nishikawa T, Edelstein D, Du XL, Yamagishi S, Matsumura T, Kaneda Y, Yorek MA, Beebe D, Oates PJ, Hammes HP, et al. 2000 Normalizing mitochondrial superoxide production blocks three pathways of hyperglycaemic damage. Nature $\mathbf{4 0 4}$ 787-790. (https://doi. org/10.1038/35008121)

Otani K, Ishihara S, Yamaguchi H, Murono K, Yasuda K, Nishikawa T, Tanaka T, Kiyomatsu T, Hata K, Kawai K, et al. 2017 Adiponectin and https://erc.bioscientifica.com

https://doi.org/10.1530/ERC-21-0092 (c) 2021 Society for Endocrinology Published by Bioscientifica Ltd. Printed in Great Britain 
colorectal cancer. Surgery Today 47 151-158. (https://doi.org/10.1007/ s00595-016-1334-4)

Parida S, Siddharth S \& Sharma D 2019 Adiponectin, obesity, and cancer: clash of the bigwigs in health and disease. International Journal of Molecular Sciences 20 2519. (https://doi.org/10.3390/ijms20102519)

Park H, Kim M, Kwon GT, Lim DY, Yu R, Sung MK, Lee KW, Daily JW \& Park JHY 2012 A high-fat diet increases angiogenesis, solid tumor growth, and lung metastasis of CT26 colon cancer cells in obesityresistant BALB/c mice. Molecular Carcinogenesis 51 869-880. (https:// doi.org/10.1002/mc.20856)

Porporato PE, Filigheddu N, Pedro JMBS, Kroemer G \& Galluzzi L 2018 Mitochondrial metabolism and cancer. Cell Research 28 265-280. (https://doi.org/10.1038/cr.2017.155)

Ren J, Sui H, Fang F, Li Q \& Li B 2019 The application of Apc Min/+ mouse model in colorectal tumor researches. Journal of Cancer Research and Clinical Oncology 145 1111-1122. (https://doi. org/10.1007/s00432-019-02883-6)

Rowlands MA, Holly JMP, Hamdy F, Phillips J, Goodwin L, Marsden G, Gunnell D, Donovan J, Neal DE \& Martin RM 2012 Serum insulinlike growth factors and mortality in localised and advanced clinically detected prostate cancer. Cancer Causes and Control 23 347-354. (https://doi.org/10.1007/s10552-011-9883-8)

Santinon G, Pocaterra A \& Dupont S 2016 Control of YAP/TAZ activity by metabolic and nutrient-sensing pathways. Trends in Cell Biology 26 289-299. (https://doi.org/10.1016/j.tcb.2015.11.004)

Sciacovelli M, Gaude E, Hilvo M \& Frezza C 2014 The metabolic alterations of cancer cells. Methods in Enzymology 542 1-23. (https:// doi.org/10.1016/B978-0-12-416618-9.00001-7)

Sebastián C, Zwaans BMM, Silberman DM, Gymrek M, Goren A, Zhong L, Ram O, Truelove J, Guimaraes AR, Toiber D, et al. 2012 The histone deacetylase SIRT6 Is a tumor suppressor that controls cancer metabolism. Cell 151 1185-1199. (https://doi.org/10.1016/j. cell.2012.10.047)

Sekharam M, Zhao H, Sun M, Fang Q, Zhang Q, Yuan Z, Dan HC, Boulware D, Cheng JQ \& Coppola D 2003 Insulin-like growth factor 1 receptor enhances invasion and induces resistance to apoptosis of colon cancer cells through the Akt/Bcl-x(L) pathway. Cancer Research 63 7708-7716.

Stastna M, Janeckova L, Hrckulak D, Kriz V \& Korinek V 2019 Human colorectal cancer from the perspective of mouse models. Genes $\mathbf{1 0}$ 788. (https://doi.org/10.3390/genes10100788)

Stojsavljević S, Virović Jukić L, Kralj D \& Duvnjak M 2016 The relationship between insulin resistance and colon cancer. Endocrine Oncology and Metabolism 2 24-33. (https://doi.org/10.21040/eom/2016.2.3)

Su X, Wellen KE \& Rabinowitz JD 2016 Metabolic control of methylation and acetylation. Current Opinion in Chemical Biology 30 52-60. (https://doi.org/10.1016/j.cbpa.2015.10.030)

Teng JA, Wu SG, Chen JX, Li Q, Peng F, Zhu Z, Qin J \& He ZY 2016 The activation of ERK1/2 and JNK MAPK signaling by insulin/IGF-1 is responsible for the development of colon cancer with type 2 diabetes mellitus. PLoS ONE 11 e0149822. (https://doi.org/10.1371/ journal.pone.0149822)

Teraoka N, Mutoh M, Takasu S, Ueno T, Nakano K, Takahashi M, Imai T, Masuda S, Sugimura T \& Wakabayashi K 2011 High susceptibility to azoxymethane-induced colorectal carcinogenesis in obese KK-Ay mice. International Journal of Cancer 129 528-535. (https://doi. org/10.1002/ijc.25711)
Tiwari A, Saraf S, Verma A, Panda PK \& Jain SK 2018 Novel targeting approaches and signaling pathways of colorectal cancer: an insight. World Journal of Gastroenterology 24 4428-4435. (https://doi. org/10.3748/wjg.v24.i39.4428)

Togliatto G, Dentelli P \& Brizzi MF 2015 Skewed epigenetics: an alternative therapeutic option for diabetes complications. Journal of Diabetic Research 2015 373708. (https://doi. org/10.1155/2015/373708)

Uyar GO \& Sanlier N 2019 Association of adipokines and insulin, which have a role in obesity, with colorectal cancer. Eurasian Journal of Medicine 51 191-195. (https://doi.org/10.5152/ eurasianjmed.2018.18089)

Vasconcelos-dos-Santos A, Loponte HFBR, Mantuano NR, Oliveira IA, de Paula IF, Teixeira LK, De-Freitas-Junior JCM, Gondim KC, Heise N, Mohana-Borges R, et al. 2017 Hyperglycemia exacerbates colon cancer malignancy through hexosamine biosynthetic pathway. Oncogenesis 6 e306-e306. (https://doi.org/10.1038/oncsis.2017.2)

Vella V, Milluzzo A, Scalisi NM, Vigneri P \& Sciacca L 2018 Insulin receptor isoforms in cancer. International Journal of Molecular Sciences 19 3615. (https://doi.org/10.3390/ijms19113615)

Vera R, Aparicio J, Carballo F, Esteva M, González-Flores E, Santianes J, Santolaya F \& Fernández-Cebrián JM 2019 Recommendations for follow-up of colorectal cancer survivors. Clinical and Translational Oncology 21 1302-1311. (https://doi.org/10.1007/s12094-019-02059-1)

Vigneri PG, Tirrò E, Pennisi MS, Massimino M, Stella S, Romano C \& Manzella L 2015 The insulin/IGF system in colorectal cancer development and resistance to therapy. Frontiers in Oncology 5230. (https://doi.org/10.3389/fonc.2015.00230)

Warburg O 1956 Respiration the origin of cancer cells. Science 123 309-314. (https://doi.org/10.1126/science.123.3191.309)

Wittekind C 2015 The development of the TNM classification of gastric cancer. Pathology International 65 399-403. (https://doi.org/10.1111/ pin.12306)

Yagi T, Kubota E, Koyama H, Tanaka T, Kataoka H, Imaeda K \& Joh T 2018 Glucagon promotes colon cancer cell growth via regulating AMPK and MAPK pathways. Oncotarget 9 10650-10664. (https://doi. org/10.18632/oncotarget.24367)

Yang M, Soga T \& Pollard PJ 2013 Oncometabolites: linking altered metabolism with cancer. Journal of Clinical Investigation 123 3652-3658. (https://doi.org/10.1172/JCI67228)

Yau SW, Azar WJ, Sabin MA, Werther GA \& Russo VC 2015 IGFBP-2 taking the lead in growth, metabolism and cancer. Journal of Cell Communication and Signaling 9 125-142. (https://doi.org/10.1007/ s12079-015-0261-2)

Zhang X, Zhao XW, Liu DB, Han CZ, Du LL, Jing JX \& Wang Y 2014 Lipid levels in serum and cancerous tissues of colorectal cancer patients. World Journal of Gastroenterology 20 8646-8652. (https://doi. org/10.3748/wjg.v20.i26.8646)

Zhang Q, Wang L, yu SZ \& Qu Jr X 2015 Knockdown of type I insulinlike growth factor receptor inhibits human colorectal cancer cell growth and downstream PI3K/Akt, WNT/ $\beta$-catenin signal pathways. Biomedicine and Pharmacotherapy 73 12-18. (https://doi.org/10.1016/j. biopha.2015.05.004)

Ziech D, Franco R, Pappa A \& Panayiotidis MI 2011 Reactive oxygen species (ROS) - induced genetic and epigenetic alterations in human carcinogenesis. Mutation Research 711 167-173. (https://doi. org/10.1016/j.mrfmmm.2011.02.015)

Received in final form 23 March 2021

Accepted 31 March 2021

Accepted Manuscript published online 27 April 2021 https://erc.bioscientifica.com https://doi.org/10.1530/ERC-21-0092
C) 2021 Society for Endocrinology Published by Bioscientifica Ltd. Printed in Great Britain 